\title{
Determinants of breastfeeding initiation and its association with breastfeeding practice of Filipino children aged 0-23 months
}

\author{
Mildred O. Guirindola*, Ma. Lynell V. Maniego, Keren Faye M. Gaya, \\ $\mathcal{E}$ Cecilia Cristina S. Acuin
}

Nutritional Assessment and Monitoring Division (NAMD), Food and Nutrition Research Institute

(FNRI), Department of Science and Technology (DOST)

\begin{abstract}
Early initiation of breastfeeding, defined as breastfeeding within $1 \mathrm{~h}$ after delivery, ensures that the child will receive its first protection from the immunoglobulins found in colostrum. It also helps establish exclusive breastfeeding which is the optimal feeding practice for infants from birth to 6 months. The study aimed to identify the variables of breastfeeding initiation among Filipino children aged 0-23 months and to associate child's breastfeeding initiation with the child's breastfeeding practice during the first two years of life. The study was a cross-sectional analysis of the $8^{\text {th }}$ National Nutrition Survey (NNS) collected in 2013 which included a national data of 4,960 mother and child pair. Multiple logistic regression was used to identify the determinants of breastfeeding initiation. The association between breastfeeding initiation and the child's feeding practice at the time of the survey was tested using Chi square test at $5 \%$ level of significance. Results showed that mothers who gave birth to a full term infants (Adjusted Odds Ration [AOR] 1.9; 95\% Confidence Interval [CI] 1.19, 3.04), who had given birth more than once (AOR 1.2; 95\% CI 1.00, 1.53) and those who had given birth in a public health center (AOR 1.5; 95\% CI 1.08, 2.22) were associated with increased odds of early initiation of breastfeeding. Significant association was also found between infants' breastfeeding initiation and breastfeeding practices at the time of the survey. Factors affecting early initiation of breastfeeding were gestational age at birth, parity, method of delivery, place of delivery, and household wealth quintile. The study provided evidence that there is a need to improve promotion of timely breastfeeding initiation and for the government to strengthen its campaign on Mother-Baby Friendly Hospital Initiative (MBFHI), setting goals that all health delivery facilities in the country are Mother-Baby Friendly certified.
\end{abstract}

Keywords: exclusive breastfeeding, breastfeeding initiation, infant and young child feeding

\section{INTRODUCTION}

One of the core indicators of the World Health Organization - United Nations Children's Fund

*To whom correspondence should be addressed: mildredguirindola@gmail.com
(WHO-UNICEF) on Infant and Young Child Feeding (IYCF) is timely initiation of breastfeeding, which should be immediately or within one hour after birth. The child who is initiated to breastfeed immediately after birth increases the likelihood of survival as compared 
to the child who is not [1]. It saves lives as immediate skin to skin contact fosters bonding between the mother and the child and keeps the baby warm, regulates body's temperature and prevents hypothermia [2].

Early initiation of breastfeeding ensures that the child will receive its first immunization from the "colostrum" in milk. Colostrum is secreted in the first 2-3 days after delivery, thus infants with delayed breastfeeding initiation for three days will not likely to get it. Colostrum is known for its protective benefits as it is clean, and contains antibodies that will keep the child from pathogens that bring illnesses and infections such as sepsis and diarrhea. Frequent suckling of the baby will also stimulate the production of breastmilk that will lead to the establishment of exclusive breastfeeding and facilitate sustained breastfeeding throughout infancy [2].

Early breastfeeding also boosts mother's confidence to breastfeed and promotes motherbaby bonding which is one of the key factors for a successful breastfeeding. Breastfeeding is also economical since breastfed babies are less likely to get sick and can save money intended to buy formula milk [3].

In response to the global strategies on BabyFriendly Hospital Initiative (BFHI) launched by WHO in 1991, the Philippines enacted Republic Act 7600 also known as the Rooming-in and Breastfeeding Act of 1992 and was amended by RA 10028 in 2009 as the "Expanded Breastfeeding Promotion Act of 2009”. In 2007, The Department of Health issued AO No. 20070026 to promote breastfeeding by guiding health workers in revitalizing and sustaining motherbaby friendly hospitals [4]. Also in 2009, AO 2009-0025 - Adopting New Policies and Protocol on Essential Newborn Care was implemented to ensure the provision of globally evidence-based essential newborn care focusing on the first week of life [5].
This cross-sectional study looked at the factors associated with breastfeeding initiation in the country using secondary data from the DOSTFNRI's $8^{\text {th }}$ National Nutrition Survey done in 2013. Specifically, it aimed to identify the infant, maternal and household factors affecting initiation of breastfeeding and associate infant's breastfeeding initiation with the infant's breastfeeding practice at the time of the survey. This paper is also an important input in tracking progress on breastfeeding initiation, being one of the indicators of the Philippine IYCF Strategic Plan of Action for 2011-2016 towards reduction of child mortality and morbidity.

\section{Methods}

Sampling design. The $8^{\text {th }}$ NNS adopted the Master Sample (MS) developed by the Philippine Statistical Authority (PSA).The survey employed a stratified three-stage sampling design. The first stage is the selection of Primary Sampling Units (PSUs), which is defined as a barangay or a combination of contiguous barangays with at least 500 households each. From these, enumeration areas (EAs) were drawn. An EA is a barangay or part thereof consisting of 150-200 households. The third and final stage of sampling was the random selection of households as the ultimate sampling units where all the eligible children came from. All children 0-23 months in the sample households coming from four replicates, where each replicate is capable of providing national estimates with adequate precision, were included in the study.

Data collection. The child's profile and household and maternal characteristics were collected through face-to-face interview with the mother using a pre-tested questionnaire installed in the electronic Data Collection System (e-DCS). To identify the child's breastfeeding practices, child's actual food intake the previous day was asked to the mother or primary caregiver through a 24-h food recall 
using a paper-based questionnaire and measuring tools.

\section{Variables}

Independent variables. Selected maternal, infant and household characteristics were the independent variables. Maternal variables refer to mother characteristics which include mother's age calculated in years $(<20,20-29$, and $\geq 30$ years old); maternal highest level of education (no schooling, elementary, high school, vocational and college education); parity or number of live births in her lifetime, (categorized as $1,2-3,4-5$, and $\geq 6$ ); delivery characteristics with the youngest child which includes method of delivery (vaginal or caesarean); place of delivery (home, private hospital, public hospital, public health center); birth attendant (health professionals, traditional birth attendant or hilot); and ante-natal care (as received or did not receive).

Infant variables were birth weight (low birth weight at $<2500 \mathrm{~g}$ or normal birth weight at $\geq 2500$ g) and gestational age at birth (pre-term or full-term). Household wealth quintile (poorest, poor, middle, rich, and richest) and area of residence (urban or rural) were considered as component of the household profile.

Dependent variables. The dependent variables in this study were breastfeeding initiation and breastfeeding practices. Breastfeeding initiation is defined as breastfeeding within $1 \mathrm{~h}$ after birth. The operational definition of breastfeeding practices used in this study was adopted from the WHO-UNICEF Indicators for Assessing Infant and Young Child Feeding Practices based on the child's feeding the previous day and night: a) exclusive breastfeeding is a feeding practice where the infant receives nothing else but breast milk (including expressed breast milk or breast milk from a wet nurse) with the exception of oral rehydration solutions (ORS), drops, and syrup (vitamins, minerals and medicines); b) predominant breastfeeding is defined as a feeding practice where breast milk (including expressed breast milk or breast milk from a wet nurse) is the predominant source of nourishment and certain liquids (water, waterbased fluids, fruit juice), ORS, vitamins and medicines are allowed to be consumed; c) breastfeeding with complementary, a feeding practice where the infant receives breast milk and complementary food at the same time; and, d) not breastfeeding which is a feeding practice where infants do not receive any breast milk in their diet.

Statistical analysis. Multiple logistic regression was used to identify the determinants of breastfeeding initiation. The association between breastfeeding initiation and child's feeding practice at the time of the survey was tested using Chi-square test at 5\% level of significance.

Ethical consideration. The $8^{\text {th }}$ NNS was approved by the Ethics Review Committee of the FNRI-DOST. Information on the objectives and principles of the survey was given to the mother/primary caregiver of children 0-23 months who then gave their oral and written consent to participate in the survey.

\section{Results}

The study covered a total of 4,960 infants and young children. Children who are of 12-23 months of age consisted half $(50.3 \%)$ of the subjects, while infants of $0-5$ and $6-11$ months of age comprised the $23.6 \%$ and $26.1 \%$ of the subjects, respectively.

Infant, maternal and household characteristics. Table 1 summarizes the infant, maternal, and socio-demographic profile of the mother-infant participants in the study. Almost all (97.1\%) of the infants were delivered full term, while very few (2.9\%) were delivered premature. Meanwhile, $74.8 \%$ of all the infants were 
Table 1. Percentage distribution of infant, maternal and socio-demographic profile of children 0-23 months: Philippine, 2013 $(n=4,960)$

\begin{tabular}{|c|c|}
\hline Characteristics & Proportion \\
\hline \multicolumn{2}{|c|}{ Infant's Profile } \\
\hline \multicolumn{2}{|c|}{ Gestational age at birth } \\
\hline Preterm & 2.9 \\
\hline Full term & 97.1 \\
\hline$\geq 2500$ & 74.8 \\
\hline$<2500$ & 25.2 \\
\hline \multicolumn{2}{|c|}{ Maternal Profile } \\
\hline \multicolumn{2}{|l|}{ Method of delivery } \\
\hline Normal & 88.9 \\
\hline Caesarean & 11.1 \\
\hline \multicolumn{2}{|l|}{ Place of delivery } \\
\hline At home & 26.9 \\
\hline Public hospital & 34.9 \\
\hline Private hospital/clinic & 20.4 \\
\hline Public health center/clinic & 17.6 \\
\hline Others & 0.2 \\
\hline \multicolumn{2}{|l|}{ Assistance during delivery } \\
\hline $\begin{array}{l}\text { Doctor/Nurse/Midwife } \\
\text { nad }\end{array}$ & 81.8 \\
\hline Traditional birth attendant & 17.5 \\
\hline Others & 0.7 \\
\hline \multicolumn{2}{|l|}{ Age at birth } \\
\hline$<20$ & 7.4 \\
\hline $20-29$ & 41.3 \\
\hline$\geq 30$ & 51.3 \\
\hline \multicolumn{2}{|l|}{ Educational level } \\
\hline No grade completed & 1.2 \\
\hline Elementary undergraduate & 6.9 \\
\hline Elementary graduate & 10.4 \\
\hline High school undergraduate & 16.7 \\
\hline High school graduate & 36.2 \\
\hline Vocational undergraduate & 1.2 \\
\hline Vocational graduate & 3.8 \\
\hline College undergraduate & 11.5 \\
\hline College graduate & 12.1 \\
\hline \multicolumn{2}{|l|}{ Parity } \\
\hline 1 & 31.0 \\
\hline $2-3$ & 40.0 \\
\hline $4-5$ & 17.6 \\
\hline$\geq 6$ & 11.5 \\
\hline \multicolumn{2}{|c|}{$\begin{array}{l}\text { Received counselling on nutrition / } \\
\text { IYCF during antenatal care }\end{array}$} \\
\hline No & 19.3 \\
\hline Yes & 80.7 \\
\hline \multicolumn{2}{|c|}{$\begin{array}{c}\text { Socio-demographic Profile } \\
\end{array}$} \\
\hline \multicolumn{2}{|l|}{ Wealth quintile } \\
\hline Poorest & 23.6 \\
\hline Poor & 21.8 \\
\hline Middle & 20.4 \\
\hline Rich & 18.5 \\
\hline Richest & 15.7 \\
\hline \multicolumn{2}{|l|}{ Area of residence } \\
\hline Rural & 48.7 \\
\hline Urban & 51.3 \\
\hline
\end{tabular}

delivered weighing $2500 \mathrm{~g}$ or heavier and onefourth (25.2\%) were of low birth weight.

About nine out of ten children were delivered normally, while one out of ten children was delivered via caesarean section. Of these deliveries, $26.9 \%$ were delivered at home, 34.9\% were delivered at public hospitals, and the rest were delivered at private hospitals (20.4\%) and public health centers (17.6\%). Majority (81.8\%) of the deliveries were with the assistance of skilled birth attendants (doctors, midwives and nurses), while some (17.5\%) were with the help of traditional birth attendants (TBA) or hilot.

A great majority of the mothers were more than 20 years old (92.6\%) during the survey. Many were high school graduates (36.2\%), had given birth at least twice (40\%) in her lifetime and received counselling on nutrition during antenatal care $(80.7 \%)$ while pregnant with the youngest child.

A high percentage of the children belonged to the poorest (23.6\%), poor (21.8\%) and middle wealth quintiles (20.4\%). There was an almost equal distribution of children living in rural (48.7\%) and urban areas (51.3\%).

Breastfeeding initiation. In the Philippines, about eight in every ten children (77.1\%) were initiated to breastfeeding within $1 \mathrm{~h}$ after delivery. About one out of eight children (12.8\%) was initiated to breastfeeding after less than 1 day while one out of ten (10.1\%) was initiated after more than 1 day after delivery.

Timely initiation of breastfeeding was found to be significantly associated with infant's gestational age at birth $(p<0.01)$. Breastfeeding initiation within $1 \mathrm{~h}$ after delivery was higher among full term infants (77.1\%) than those who were born preterm (57.9\%). However, birth weight and breastfeeding initiation were not significantly associated ( $p=0.1839$ ); infants with birth weight $\geq 2500$ g (76.7\%) and LBW infants 
Table 2. Percentage distribution of infant, maternal and socio-demographic characteristics at birth by timing of breastfeeding initiation: Philippines, $2013(n=4,960)$

\begin{tabular}{|c|c|c|c|c|}
\hline \multirow[b]{2}{*}{ Characteristics } & \multicolumn{3}{|c|}{ Timing of Breastfeeding Initiation } & \multirow[b]{2}{*}{$p$-value } \\
\hline & $\begin{array}{l}\text { Within } \\
1 \text { hour }\end{array}$ & $\begin{array}{c}\text { Less than } \\
1 \text { day }\end{array}$ & $\begin{array}{c}\text { More than } \\
1 \text { day }\end{array}$ & \\
\hline \multicolumn{5}{|c|}{ Infant's Profile } \\
\hline \multicolumn{4}{|l|}{ Gestational age at birth } & \multirow{3}{*}{$0.0000^{*}$} \\
\hline Preterm & 57.9 & 14.1 & 28.0 & \\
\hline Full term & 77.1 & 13.2 & 9.8 & \\
\hline \multicolumn{4}{|l|}{ Birth weight } & \multirow{3}{*}{0.1839} \\
\hline$\geq 2500$ & 76.7 & 13.6 & 9.8 & \\
\hline$<2500$ & 76.3 & 12.0 & 11.7 & \\
\hline \multicolumn{5}{|c|}{ Maternal Profile } \\
\hline \multicolumn{4}{|l|}{ Age at birth } & \multirow{4}{*}{0.0813} \\
\hline$<20$ & 75.8 & 14.0 & 10.2 & \\
\hline $20-29$ & 75.3 & 13.5 & 11.3 & \\
\hline$\geq 30$ & 79.0 & 12.0 & 9.0 & \\
\hline \multicolumn{4}{|l|}{ Educational level } & \multirow{10}{*}{$0.0000^{*}$} \\
\hline No grade completed & 86.5 & 10.2 & 3.4 & \\
\hline Elementary undergraduate & 82.5 & 8.7 & 8.8 & \\
\hline Elementary graduate & 78.8 & 12.9 & 8.3 & \\
\hline High school undergraduate & 77.6 & 11.9 & 10.5 & \\
\hline High school graduate & 77.2 & 13.7 & 9.0 & \\
\hline Vocational undergraduate & 62.6 & 16.9 & 20.6 & \\
\hline Vocational graduate & 74.6 & 16.3 & 9.1 & \\
\hline College undergraduate & 79.4 & 11.7 & 9.0 & \\
\hline College graduate & 66.2 & 15.8 & 18.0 & \\
\hline \multicolumn{4}{|l|}{ Parity } & \multirow{5}{*}{$0.0005^{*}$} \\
\hline 1 & 72.5 & 14.5 & 13.0 & \\
\hline $2-3$ & 76.9 & 12.6 & 10.5 & \\
\hline $4-5$ & 80.0 & 11.3 & 8.7 & \\
\hline$\geq 6$ & 80.9 & 13.3 & 5.8 & \\
\hline \multicolumn{4}{|c|}{ Received counselling on nutrition / IYCF during antenatal care } & \multirow{3}{*}{0.7500} \\
\hline Yes & 76.3 & 13.3 & 10.5 & \\
\hline No & 77.3 & 13.2 & 9.5 & \\
\hline \multicolumn{4}{|l|}{ Method of delivery } & \multirow{3}{*}{$0.0000^{*}$} \\
\hline Normal & 78.9 & 12.4 & 8.7 & \\
\hline Caesarean & 56.4 & 20.1 & 23.6 & \\
\hline Assistance during delivery & & & & \\
\hline Health professionals & 75.9 & 13.5 & 10.6 & \\
\hline TBA & 79.3 & 11.9 & 8.8 & 0.1609 \\
\hline Others & 87.6 & 9.3 & 3.1 & \\
\hline Place of delivery & & & & \\
\hline At home & 79.0 & 11.8 & 9.3 & \\
\hline Public hospital & 76.5 & 13.6 & 9.9 & \\
\hline Private hospital & 67.6 & 16.9 & 15.5 & $0.0000^{*}$ \\
\hline Public health center & 82.9 & 10.2 & 6.9 & \\
\hline Others & 70.9 & 29.1 & 0.0 & \\
\hline & -demogra & c Profile & & \\
\hline Wealth quintile & & & & \\
\hline Poorest & 82.4 & 11.2 & 6.5 & \\
\hline Poor & 79.1 & 11.1 & 9.8 & \\
\hline Middle & 78.4 & 13.1 & 8.6 & $0.0000^{*}$ \\
\hline Rich & 75.6 & 13.4 & 11.1 & \\
\hline Richest & 66.2 & 16.5 & 17.3 & \\
\hline Area of residence & & & & \\
\hline $\begin{array}{l}\text { Rural } \\
\text { nal }\end{array}$ & 78.5 & 12.6 & 8.9 & 0.0717 \\
\hline Urban & 75.8 & 13.0 & 11.2 & \\
\hline
\end{tabular}

*Statistically significant at $p<0.05$ 
(76.3\%) with timely initiation of breastfeeding were of almost the same percentage (Table 2).

A slightly higher percentage of mothers who were 30 years and older (79.0\%) have timely breastfeeding initiation, compared to teenage mothers (75.8\%) and mothers who were 20-29 years old (75.3\%). However, the age of mothers during delivery was not found to have a significant effect on timely initiation of breastfeeding $(p=0.0813)$.

The educational attainment of the mother has a significant association with the timely initiation of breastfeeding $(p<0.01)$. The highest percentage with timely initiation was observed among mothers who had not completed any grade level (86.5\%), while the lowest proportion was found among mothers who were undergraduate of vocational courses (62.6\%). On the other hand, mothers who finished college education were among those who had the highest percentage of breastfeeding initiation beyond 1 day (18.0\%).

A significant association was also found between timely initiation of breastfeeding and parity $(p<0.01)$. A high proportion $(80.9 \%)$ with timely breastfeeding initiation was observed among mothers with six or more children, whereas mother with only one child had the least (72.5\%). The proportion with timely breastfeeding initiation increased with increasing parity.

Although not statistically significant $(p=0.7500)$, mothers who did not receive nutrition counselling during their prenatal care had slightly higher proportion of timely initiation of breastfeeding (77.3\%) than those who received nutrition counselling (76.3\%).

The percentage of infants initiated to breastfeeding within $1 \mathrm{~h}$ was significantly associated with mother's type of birth delivery $(p<0.01)$. Infants born via normal delivery had higher percentage of timely breastfeeding
Table 3. Logistic regression model of factors associated to breastfeeding initiation: Philippines, $2013(n=4,960)$

\begin{tabular}{|c|c|c|}
\hline Characteristics & AOR & $p$-value \\
\hline \multicolumn{3}{|c|}{ Gestational age at birth } \\
\hline Preterm & \multicolumn{2}{|c|}{ Reference category } \\
\hline Full term & 1.902 & $0.007 *$ \\
\hline \multicolumn{3}{|c|}{ Birthweight } \\
\hline$\geq 2500$ & \multicolumn{2}{|c|}{ Reference categor } \\
\hline$<2500 \mathrm{~g}$ & 0.888 & 0.301 \\
\hline \multicolumn{3}{|c|}{ Mother's age at birth } \\
\hline$<20$ & \multicolumn{2}{|c|}{ Reference category } \\
\hline $20-29$ & 1.009 & 0.955 \\
\hline$\geq 30$ & 1.249 & 0.245 \\
\hline \multicolumn{3}{|c|}{ Mother's educational attainment } \\
\hline No grade completed & \multicolumn{2}{|c|}{ Reference category } \\
\hline Elementary undergraduate & 0.632 & 0.367 \\
\hline Elementary graduate & 0.509 & 0.176 \\
\hline HS undergraduate & 0.457 & 0.114 \\
\hline HS graduate & 0.505 & 0.166 \\
\hline Vocational undergraduate & 0.266 & 0.025 \\
\hline Vocational graduate & 0.568 & 0.290 \\
\hline College undergraduate & 0.664 & 0.419 \\
\hline College graduate & 0.435 & 0.099 \\
\hline \multicolumn{3}{|l|}{ Parity } \\
\hline 1 & \multicolumn{2}{|c|}{ Reference category } \\
\hline $2-3$ & 1.238 & 0.046 \\
\hline $4-5$ & 1.176 & 0.304 \\
\hline$\geq 6$ & 1.059 & 0.763 \\
\hline \multicolumn{3}{|c|}{$\begin{array}{c}\text { Received counselling on nutrition / } \\
\text { IYCF during antenatal care }\end{array}$} \\
\hline No & \multicolumn{2}{|c|}{ Reference category } \\
\hline Yes & 1.116 & 0.315 \\
\hline \multicolumn{3}{|c|}{ Place of delivery } \\
\hline At home & \multicolumn{2}{|c|}{ Reference category } \\
\hline Public hospital & 1.224 & 0.218 \\
\hline Private hospital/Clinic/Lying-in & 0.962 & 0.827 \\
\hline Public health center & 1.549 & $0.017 *$ \\
\hline Others & 0.451 & 0.315 \\
\hline \multicolumn{3}{|c|}{ Type of delivery } \\
\hline Normal & \multicolumn{2}{|c|}{ Reference category } \\
\hline Caesarean & 0.413 & $0.000^{*}$ \\
\hline \multicolumn{3}{|c|}{ Assistance during delivery } \\
\hline Doctor/Nurse/Midwife & \multicolumn{2}{|c|}{ Reference category } \\
\hline TBA & 0.985 & 0.934 \\
\hline Others & 1.773 & 0.346 \\
\hline \multicolumn{3}{|c|}{ Wealth quintile } \\
\hline Poorest & \multicolumn{2}{|c|}{ Reference category } \\
\hline Poor & 0.737 & $0.016^{*}$ \\
\hline Middle & 0.779 & 0.076 \\
\hline Rich & 0.628 & $0.002^{*}$ \\
\hline Richest & 0.454 & $0.000^{*}$ \\
\hline \multicolumn{3}{|c|}{ Area of residence } \\
\hline Rural & \multicolumn{2}{|c|}{ Reference category } \\
\hline Urban & 1.127 & 0.197 \\
\hline Constant & 3.289 & 0.058 \\
\hline
\end{tabular}


initiation (78.9\%) than those who were delivered through caesarean section (56.4\%). The person who assisted the deliveries, whether from professional birth attendant (75.9\%) or from traditional birth attendant (79.3\%), did not have significant association on the timely initiation of breastfeeding ( $p=0.1609$ ).

The proportion of infants initiated to breastfeeding within $1 \mathrm{~h}$ after delivery was highest among those delivered in public health center (82.9\%), while the lowest proportion was from those delivered in private hospitals (67.6\%) which in turn had the highest proportion of delayed breastfeeding initiation (15.5\%).

Wealth quintile had a significant association with timely breastfeeding initiation $(p<0.01)$. The highest proportion of children who were initiated to breastfeeding within $1 \mathrm{~h}$ belonged to the poorest quintile (82.4\%) while the least proportion was from the richest quintile (66.2\%). The area of residence, whether from rural (78.5\%) or from urban areas (75.8\%), was not significantly associated with timely breastfeeding initiation ( $p=0.0717$ ).

Determinants of breastfeeding initiation. The final model on determinants of breastfeeding initiation showed that infants with complete gestational age had 1.9 times greater odds of being initiated to breastfeeding within $1 \mathrm{~h}$ after delivery compared to infants born preterm.
Mothers who had given birth more than twice have higher odds of practicing timely breastfeeding initiation (1.2 times) compared with mothers who experienced giving birth only once (Table 3).

Infants born in public health centers had 1.5 times as likely to have timely breastfeeding initiation compared to those who were born at home and at other health facilities. On the other hand, infants born through caesarean delivery were less likely (AOR $=0.4,95 \%$ CI: $0.317,0.538$ ) to experience timely breastfeeding initiation than those who were born via normal delivery.

The odds of timely breastfeeding initiation was significantly lower among the richer $(\mathrm{AOR}=0.6$, 95\% CI: $0.466,0.847)$ and richest $(\mathrm{AOR}=0.5$, $95 \%$ CI: $0.323,0.637)$ wealth quintiles than the poorest quintile.

\begin{abstract}
Association between breastfeeding initiation and breastfeeding practices. The proportion of infants $0-5$ months with timely breastfeeding initiation revealed a significant association $(p<0.01)$ with breastfeeding practices (Table 4). Among 0-5-month old infants, higher proportions who were initiated to breastfeeding within $1 \mathrm{~h}$ after delivery were exclusively breastfed at the time of the survey. However, it was noted that predominant breastfeeding was also higher among 0-5-month old infants with timely breastfeeding initiation.
\end{abstract}

Table 4. Association between breastfeeding initiation and breastfeeding practices among children 0-23 months by age in months: Philippines, $2013(n=4,960)$

\begin{tabular}{|c|c|c|c|c|c|c|}
\hline \multirow[b]{2}{*}{$\begin{array}{l}\text { Age in } \\
\text { Months }\end{array}$} & \multirow{2}{*}{$\begin{array}{l}\text { Breastfeeding } \\
\text { Initiation }\end{array}$} & \multicolumn{5}{|c|}{ Breastfeeding Practices } \\
\hline & & $\begin{array}{c}\text { Exclusive } \\
\text { breastfeeding }\end{array}$ & $\begin{array}{l}\text { Predominant } \\
\text { breastfeeding }\end{array}$ & \begin{tabular}{|c|} 
Breastfeeding $w /$ \\
complementary
\end{tabular} & $\begin{array}{c}\text { Not } \\
\text { breastfeeding }\end{array}$ & $p$-value \\
\hline \multirow{3}{*}{$0-5$} & Within 1 hour & 60.6 & 7.7 & 16.7 & 15.0 & \multirow{3}{*}{$0.0000^{*}$} \\
\hline & Less than 1 day & 56.0 & 4.4 & 25.6 & 14.0 & \\
\hline & More than 1 day & 26.9 & 7.0 & 38.7 & 27.4 & \\
\hline \multirow{3}{*}{$6-11$} & Within 1 hour & 6.4 & 1.0 & 64.4 & 28.2 & \multirow{3}{*}{$0.0022^{*}$} \\
\hline & Less than 1 day & 3.7 & 1.6 & 57.0 & 37.8 & \\
\hline & More than 1 day & 1.7 & 2.0 & 49.5 & 46.8 & \\
\hline \multirow{3}{*}{$12-23$} & Within 1 hour & 0.4 & 0.2 & 45.5 & 54.0 & \multirow{3}{*}{0.8418} \\
\hline & Less than 1 day & 0.5 & 0.0 & 41.9 & 57.7 & \\
\hline & More than 1 day & 0.0 & 0.0 & 43.5 & 56.5 & \\
\hline
\end{tabular}

*Statistically significant at $p<0.05$ 
Among 6-11 months, higher proportions of children who were breastfed and given complementary foods have timely breastfeeding initiation. Conversely, proportion of nonbreastfed children was lower among those with timely breastfeeding initiation and higher among those with delayed initiation of breastfeeding. On the other hand, timing of breastfeeding initiation has no significant association with breastfeeding practices among older children 12-23 months old.

\section{Discussion}

Breastfeeding initiation. The national percentage $(77.1 \%)$ of timely breastfeeding initiation in 2013 was significantly higher $(p<0.01)$ than what was reported in $2011(51.9 \%)$ $[6,7]$. This was considered a big improvement, although it still fell short of the Philippine IYCF Strategic Plan of Action 2011-2016 which aimed to achieve $90 \%$ of timely breastfeeding initiation within $1 \mathrm{~h}$ after birth.

The significant increase in breastfeeding initiation rate may be attributed to government programs on maternal and child care such as the Maternal, Newborn and Child Health and Nutrition (MNCHN) Program and the Mother Baby Friendly Hospital Initiatives and increasing number of health facilities that accepted and complied with the Ten Steps to Successful Breastfeeding. National and local government unit initiatives on IYCF training were also conducted among health professionals and community health workers [8].

The final model of timely initiation of breastfeeding revealed that gestational age at birth, parity, place and type of delivery and wealth quintile were determinants of breastfeeding initiation. Infants born with complete gestational age had 1.9 times greater odds of timely breastfeeding than those who were born preterm. The Philippines belongs to the top 10 countries in the world which has the greatest number of preterm births [9], a delivery of a baby before 37 completed weeks' of gestation. It is known to be a direct cause of $27 \%$ of the 4 million neonatal deaths that occur globally every year and is considered as the world's largest killer of babies [10].

When the baby is born prematurely, mothers have more difficulty with breastfeeding and this is unfortunate because premature babies need breastmilk even more than healthy full term babies. Berde and Yalcin [11] in their study in Nigeria reported that premature babies were less likely to start breastfeeding within $1 \mathrm{~h}$ of birth because babies in this condition have peculiarities and specific characteristics that limit the abilities needed for breastfeeding within the first hour of life.

One of the methods developed made to address problems on premature babies is the "Kangaroo mother care". "Kangaroo mother care" is a method of care for preterm infants weighing less than $2500 \mathrm{~g}$ which includes thermal care through continuous skin-to-skin contact, support for exclusive breastfeeding or other appropriate feeding, and early recognition or response to illness [10]. It has been shown to reduce neonatal mortality and could save an estimated 450000 preterm newborns a year. It also ensures that clinically-able preterm babies can be initiated to breastfeed immediately after birth since skinto-skin contact is a helpful way to initiate breastfeeding [9].

Giving birth in public health center had 1.4 times likelihood of timely initiation of breastfeeding than giving birth at home and at any other health facilities. The result is parallel with the study in Ghana which cited that delivery in a government health facility is a predictor of exclusive breastfeeding which the authors attributed to the call made by WHO and UNICEF for hospitals to be centers of breastfeeding [12]. The findings were also the same as the studies in Boucle du Mouhoun, Burkina Faso [13], Northwest Ethiopia [14], and in Yobe State, Nigeria [15]. In 
addition, Woldemichael and Kibie [16] in their community-based cross sectional study in Ethiopia found out that mothers who delivered their current child at home were less likely to initiate breastfeeding early than those who delivered at health institution.

This result showed that the effort of the government to bring delivery facilities nearer and accessible to people through Rural Health Units (RHU) and Barangay Health Stations (BHS) under the Basic Emergency Obstetric and Newborn Care (BEmONC) of the Maternal, Newborn, and Child Health and Nutrition (MNCHN) is somewhat successful. That is why it is important that community health volunteers or the Community Health Team (Barangay Health Workers (BHW) and Barangay Nutrition Scholars (BNS)) be empowered and trained to provide community level care and services to women before pregnancy, during pregnancy, delivery and post-partum period to sustain the gains of the program [8].

However, the survey reported that there were still mothers who gave birth at home assisted by traditional birth attendants (hilot) which points on the need for a much stronger implementation of the policy. Home delivery has negative effect in timely breastfeeding initiation though was not significant in the final model of this study.

The Department of Health (DOH) prohibits the assistance of traditional birth attendants during delivery under AO 2008-0029 (Implementing Health Reforms for Rapid Reduction of Maternal and Neonatal Mortality) to secure the safety and to ensure the optimal health of the baby and the mother. This is also popularly known as the "No Home-birthing Policy" which is strictly implemented to discourage birth delivery at home [5]. Legesse et al. [17] on their study in Ethiopia reported that traditional birth attendants were the most influential individuals favouring the practice of discarding colostrum which was the reason why timely breastfeeding initiation was practiced less likely by mothers whose delivery was attended by traditional birth attendant. On the other hand, another study in Ethiopia by Bimerew et al. [18] explained that low proportion of timely breastfeeding initiation among mothers assisted by TBAs could be due to the difference in the health education or advice provided by health professionals to mothers compared with TBAs.

Method of delivery of the mother also had significant association with breastfeeding initiation. Normal delivery is the most common and safest way of giving birth and has a positive effect on timely breastfeeding initiation. Mothers who have normal delivery have more energy and do not need longer time to rest which can be the reason why they were able to do the rooming-in process successfully hence had immediate skin-to-skin contact with their infants. On the other hand, caesarean delivery according to Lakew is the most consistent predictor of late initiation of breastfeeding [19], since mothers who undergone caesarean section delivery usually experienced pain, tiredness and discomfort which could be the reason for not being able to breastfeed within one hour after delivery [20]. Studies from Nepal [21] also supported these findings.

Increasing number of children (parity) showed a significant association with timely breastfeeding initiation. Liben and Yesuf [22] on the same study in Ethiopia said that this might be due to reason that women update their beliefs about the benefits of breastfeeding with each birth that a mother who found the benefits of breastfeeding from her previous or first-born child will decide to breastfeed her subsequent child early. Consequently, these facts were supported by the study of Yahya and Adebayo [23] which stated that mothers who delivered their first baby have higher risk of delayed breastfeeding initiation compared with mothers who delivered their second baby. 
Wealth quintile was also found to be a significant factor for timely breastfeeding initiation. Infants of mothers who were from poor wealth quintile were likely to have timely breastfeeding initiation than infants whose mothers were from the richer quintile. Breastfeeding is not only the best way to feed an infant but it is also considered the safest and most economical.

\section{Association of breastfeeding initiation with} current breastfeeding practices. The data showed that breastfeeding initiation had significant association with breastfeeding practices. Early initiation of breastfeeding revealed a significant positive effect on the practice of exclusive breastfeeding. Moore et al. [3] stated that skin-to-skin contact between mother and infant immediately after birth aids in early breastfeeding initiation and increases the probability of exclusive breastfeeding for 1-4 months of life in addition to overall duration of breastfeeding. The proportion of $6-11$ months and 12-23 months old infants and young children who continue to breastfeed were higher among those with timely breastfeeding initiation although no longer statistically significant among 12-23 months. This means that timely breastfeeding initiation is no longer protective to older children to continue breastfeeding and thus needs a more targeted intervention for mothers with older children to continue breastfeeding.

Timely initiation of breastfeeding is important for longer duration of breastfeeding because a study on factors associated with duration of breastfeeding found out that delayed breastfeeding initiation is associated with shorter breastfeeding duration [24].

\section{Conclusion}

The final model showed that factors affecting early initiation of breastfeeding were gestational age at birth, parity, method and place of delivery, and wealth quintile. Early initiation of breastfeeding also had significant effect on breastfeeding practice of the infant. Infants who were initiated to breastfeed early tend to be exclusively breastfeed more than infants who had delayed breastfeeding initiation.

Results of the survey provided evidence on the need to further promote the Baby Friendly Hospital Initiatives in the country to support timely breastfeeding initiation and discourage the provision of breastmilk substitutes.

The government also needs to strengthen the program on prenatal care especially on nutrition counselling to empower mothers to give timely breastfeeding initiation. An intensified information campaign among health professionals, community health workers, mothers and the community in general on their important role on infant feeding also needs to be done.

\section{ACKNOWLedgements}

The authors would like to acknowledge all the researchers and DOST-FNRI technical and nontechnical staff who helped in making the data collection for this study possible, as well as all the mother respondents for their indispensable participation and cooperation in this study.

Thanks are also due to the following FNRI Technical Committee (TECCOM) members, namely: Ms. Julia G. Gubat Ms. Cristina G. Malabad and Ms. Mildred A. Udarbe for critically editing the initial draft of the paper.

\section{REFERENCES}

[1] The Partnership for Maternal, Newborn and Child Health. MNCH Knowledge Summary 2: Women's and Children's Health - Enable the Continuum of Care, pp. 1-4. (2010). http:// www.who.int/pmnch/knowlegde/publications/ summaries/ks2.pdf?ua=1 


\section{Determinants of breastfeeding initiation}

[2] WHO. Infant and young child feeding. Model chapter for textbooks for medical students and allied health professionals, pp. 1-99. (Geneva, Switzerland: WHO, 2009).

[3] Moore ER, Anderson GC, Bergman N, Dowswell T. Early skin-to-skin contact for mothers and their healthy newborn infants. The Cochrane database of systematic reviews 2012; 5:CD003519. DOI:10.1002/14651858.CD003519. pub3.

[4] Department of Health. Administrative Order 2007-0026: Revitalization of the mother-baby friendly hospital initiative in health facilities with maternity and newborn care services. (Manila: $\mathrm{DOH}, 2007)$.

[5] Department of Health. Administrative Order No. 2008-0029: Implementing Health Reforms for Rapid Reduction of Maternal and Neonatal Mortality. (Manila: DOH, 2008).

[6] Food and Nutrition Research Institution Department of Science and Technology (FNRIDOST). Philippine Nutrition Facts and Figures 2013. Maternal Health and Nutrition and Infant and young Child Feeding Surveys. (Taguig City, Metro Manila: DOST, 2015).

[7] Food and Nutrition Research Institution Department of Science and Technology (FNRIDOST). Philippine Nutrition Facts and Figures 2011. (Taguig City, Metro Manila: DOST, 2012).

[8] Department of Health. The MNCHN Manual of Operation 2011. (Manila: DOH, 2011).

[9] March of Dimes, PMNCH, Save the Children, WHO. In: Howson CP, Kinney MV, Lawn JE (Eds.) Born Too Soon: The Global Action Report on Preterm Birth. (Geneva, Switzerland: WHO, 2012).

[10] Lawn JE, Mwansa-Kambafwile J, Horta BL, Barros FC, Cousens S. "Kangaroo mother care" to prevent neonatal deaths due to preterm birth complications. International Journal of Epidemiology 2010; 39(S1):i144-i154. DOI:10.1093/ije/dyq031

[11] Berde AS and Yalcin SS. Determinants of early initiation of breastfeeding in Nigeria: a populationbased study using the 2013 demograhic and health survey data. BMC Pregnancy and Childbirth. 2016;16:32. DOI:10.1186/s12884016-0818-y

[12] Tampah-Naah AM and Kyereme AK. Determinants of exclusive breastfeeding among mothers in Ghana: a cross-sectional study. International Breastfeeding Journal 2013; 8(1):1.
[13] Cresswell JA, Ganaba R, Sarrassat S, Cousens $S$, Some' $H$, Diallo $A H$, et al. Predictors of exclusive breastfeeding and consumption of soft, semi-solid or solid food among infants in Boucle du Mouhoun, Burkina Faso: A crosssectional survey. PLOS ONE 2017; 12(6):e0179593. DOI:10.1371/journal.pone. 0179593

[14] Biks GA, Tariku A, Tessema GA. Effects of antenatal care and institutional delivery on exclusive breastfeeding practice in northwest Ethiopia: a nested case-control study. International Breastfeeding Journal 2015; 10:30. DOI:10.1186/s13006-015-0055-4

[15] Bolanle A. Apparaisal of nursing mother's knowledge and practice of exclusive breastfeeding in Yobe State, Nigeria. Journal of Biology, Agriculture and Healthcare 2013; 3:20. www.iiste.org

[16] Gelete BW, Addisu YK, Haile MT. Timely Initiation of Breastfeeding and Its Associated Factors among Mothers in Tiyo Woreda, Arsi Zone, Ethiopia: A Community- Based Cross Sectional Study. Clinics Mother Child Health 2016; 13:221. DOI:10.4172/2090-7214.1000221

[17] Legesse M, Demena M, Mesfin F, Haile D. Factors Associated with Colostrum Avoidance Among Mothers of Children Aged less than 24 Months in Raya Kobo district, North-eastern Ethiopia: Community-based Cross-sectional Study. Journal of Tropical Pediatrics 2015; 61(5):357363. DOI:10.1093/tropej/fmv039

[18] Bimerew A, Teshome M, Kassa GM. Prevalence of timely breastfeeding initiation and associated factors in Dembecha district, North West Ethiopia: a cross-sectional study. International Breastfeeding Journal 2016; 11:28. DOI:10.1186/ s13006-016-0087-4

[19] Lakew Y, Tabar L, Haile D. Socio-medical determinants of timely breastfeeding initiation in Ethiopia: Evidence from the 2011 nationwide Demographic and Health Survey. International Breastfeeding Journal 2015;10:24. DOI:10.1186/ s13006-015-0050-9

[20] Tilahun G, Degu G, Azale T, Tigabu A. Prevalence and associated factors of timely initiation of breastfeeding among mothers at Debre Berhan town, Ethiopia: a cross-sectional study. International Breastfeeding Journal 2016;11:27. DOI:10.1186/s13006-016-0086-5 
[21] Khanal V, Scott JA, Lee AH, Karkee R, Binns CW. Factors associated with Early Initiation of Breastfeeding in Western Nepal. Tchounwou PB, ed. International Journal of Environmental Research and Public Health 2015;12(8):956274. DOI:10.3390/ijerph120809562.

[22] Liben ML, Yesuf EM. Determinants of early initiation of breastfeeding in Amibara district, Northeastern Ethiopia: a community based crosssectional study. International Breastfeeding Journal 2016; 11:7. DOI: 10.1186/s13006-0160067-8
[23] Yahya WB, Adebayo SB. Modelling the Trend and Determinants of Breastfeeding Initiation in Nigeria. Child Development Research 2013; 2013 Article ID 530396:9. DOI:10.1155/2013/ 53039627

[24] Chaves RG, Lamounier JA, César CC. Factors associated with duration of breastfeeding. Jornal de Pediatria 2007; 83(3):241-246. DOI:10.2223/ JPED.1610 